\title{
Rachel de Queiroz e sua escrita sertaneja
}

Laile Ribeiro de Abreu

Mestre em Literatura Brasileira / UFMG

\begin{abstract}
RESUMO
A escrita racheliana encontra o sertão como fonte de inspiração seja na ficção, na crônica ou no teatro. Sempre recorrendo à linguagem oral e tendo a mulher sertaneja com seus costumes e tradições como foco de atenção, Rachel de Queiroz inscreve-se como autora da Literatura Brasileira que contribui para a divulgação da escrita feminina.
\end{abstract}

PALAVRAS-CHAVE

Rachel de Queiroz, escrita feminina, sertão

(...) tento, com a maior insistência, embora com tão precário resultado (como se tornou evidente), incorporar a linguagem que falo e escuto no meu ambiente nativo à língua com que ganho a vida nas folhas impressas. Não que o faça por novidade, apenas por necessidade. Meu parente José de Alencar quase um século atrás vivia brigando por isso e fez escola. ${ }^{1}$

A epígrafe que utilizo para iniciar o texto ressalta um aspecto muito peculiar da obra racheliana: o uso de uma escrita que se aproxime, ao máximo, da oralidade sertaneja. Entretanto, a autora de $O$ quinze (1930) o faz sem exagerar nos caboclismos, ou seja, sem deixar que a escrita sertaneja se instaure em seu texto de maneira forçada. O que ela faz é imprimir o caráter regional a seus textos, relacionando sua escrita à terra nordestina e buscando lá, no sertão, a inspiração para construir cenários, enredos e personagens que povoam o imaginário popular de seu povo e, com isso, resgatando a cultura nordestina em todos os gêneros textuais com os quais trabalhou e, em todos, discutindo a questão de gênero com um olhar que inovou a escrita feminina.

\footnotetext{
${ }^{1}$ QUEIROZ. Cem crônicas escolhidas, p. 19.
} 
Seguindo essa trilha sertaneja, apresento alguns apontamentos dessa influência em alguns romances, peças teatrais e crônicas de Rachel de Queiroz.

Nos romances, o sertão é ponto de saída e de chegada de seus personagens, especialmente as personagens femininas, que são as que sempre protagonizam sua ficção e fazem aquele movimento de ir e vir do (para) o sertão, copiando, de certa forma, o mesmo movimento da autora, alertando para a necessidade constante de estar no sertão, o apego à terra e às tradições já identificado pela simbologia incrustada no nome de sua fazenda: "Não me deixes”.

Conceição, em $O$ quinze foge da seca, indo para o ambiente urbano, mas dedica-se, na cidade, a receber e tratar aqueles que se refugiam no "Campo de concentração" ${ }^{2}$ e, com isso, convivendo com o sertanejo e sofrendo com a seca, mesmo estando distante; Noemi, em Caminho de pedras (1937), encontra refúgio na “Casa de roupas brancas”, 3 onde costurava o dia todo, carregando no ventre o filho que não nasce antes de a narrativa encerrar-se; Maria Augusta, a Guta, em As três Marias (1939), retorna ao sertão pelo mesmo trem que a levara à cidade, reintegrando-se a seu meio, voltando a ser o que era antes, ou seja, voltando a ser do sertão; Dôra, em Dôra, Doralina (1975), depois de viver todos os amores e dores, retorna e retoma a fazenda Soledade, herança de sua família, transferindo-se do posto de Sinhazinha para o de Senhora na esperança de refazer sua vida no sertão agreste; Maria Moura, em Memorial de Maria Moura (1992), não retorna ao sertão, uma vez que de lá nunca saíra, mas incorpora, por uma questão de sobrevivência, a vida agreste e sofrida do povo sertanejo.

Romances como Dôra, Doralina e Memorial de Maria Moura, trazem protagonistas que representam o continuísmo e a ruptura com o modelo patriarcal que na época dava ao homem autoridade legal sob a mulher, filhos e agregados da família. ${ }^{4}$ São mulheres que rompem com esse modelo porque são dotadas de uma capacidade gerencial impensável para a mulher da época, contrariando a generalização que a sociedade tanto almejava. Entretanto, são mulheres que conquistaram seu espaço, usando a mesma força do homem. As matriarcas que povoam o imaginário popular, como $\mathrm{D}^{\mathrm{a}}$ Guidinha do Poço, $\mathrm{D}^{\mathrm{a}}$ Bárbara, de quem Rachel é descendente, e tantas outras que participam da memória coletiva do povo agreste, servem de inspiração para essas construções.

\footnotetext{
${ }^{2}$ Curiosamente, Rachel já utiliza em 1930 essa expressão que assombrará o mundo pelo horror da Segunda Guerra Mundial.

${ }^{3}$ QUEIROZ. Caminho de pedras, 136.

${ }^{4}$ HAHNER. A mulher brasileira e suas lutas sociais e políticas: 1850-1932, p. 29.
} 
A ficção racheliana ainda guarda outras peculiaridades que envolvem a construção feminina. Todos os romances carregam em si o fatalismo e a ausência de um final feliz. A busca pela liberdade pelas letras ou pelas armas impõe às personagens da autora cearense à solidão. A liberdade de autodeterminar-se pede a elas o sacrifício da constituição da família e da maternidade. É o preço que pagam pela rebeldia.

As duas peças de teatro que marcam a obra de Rachel de Queiroz têm o enredo bem fincado no sertão que ela conhecera tão bem e exploram temas ao gosto do povo nordestino: o cangaço e o fanatismo religioso. A primeira, Lampião (1953), trata do mundo do cangaço, resgatado da memória coletiva do homem sertanejo. Rachel Queiroz comenta em entrevista a Cadernos de Literatura Brasileira que, na verdade, escrevera a peça tendo como objetivo fazer com que Maria Bonita se sobressaísse, mas que a figura de Lampião era demasiadamente forte e que o personagem se impôs no desenrolar da escrita. ${ }^{5}$ Essa declaração da autora lembra a crítica de Mário de Andrade, na qual diz que ela

(...) se vinga do eterno masculino, lhe penetrando pouco ou mal a incapacidade de grandeza. [Seus personagens masculinos] são homens fortemente incapazes, figuras de (...) vingança, entre mulheres nítidas. Em compensação, essas vivem com riqueza esplêndida, todas descritas com uma segurança de análise, uma firmeza de tons, uma profundeza de observação verdadeiramente notáveis. ${ }^{6}$

Sobre essa fala de Mário de Andrade, Eduardo de Assis Duarte escreve que é “impossível concordar de todo com a afirmativa quando nos deparamos com a solidão de João Miguel, que nunca é resignada, ou com as proezas de Lampião, bandido e herói do sertanejo sem esperanças". ${ }^{7}$

A segunda peça de teatro, A Beata Maria do Egito (1958), teve inspiração na Santa Maria Egipcíaca, muito popular na Idade Média. A lenda da Santa chegou ao Brasil por duas vias: através do livro litúrgico Lendas douradas, do latim Flos Sanctorum, uma das principais coletâneas da vida de santos já publicada até então, e pelo folheto de Cordel Português Auto de Santa Maria Egipcíaca, que é texto considerado raro. Rachel transfere a história da Santa para a realidade nordestina, criando a Beata Maria do Egito, que, por ser devota fervorosa de Padre Cícero, lidera um movimento de fanáticos que lutam pela causa de Padim Cícero. A personagem consegue a liderança ao sacrificar sua pureza, tornando-se ímpar por lembrar as

\footnotetext{
${ }^{5}$ CADERNOS DE LITERATURA BRASILEIRA, p. 21-39.

${ }^{6}$ ANDRADE. O empalhador de passarinho, p. 117.

${ }^{7}$ DUARTE. Classe e gênero no romance de Rachel de Queiroz, p. 109.
} 
antigas hieródulas. ${ }^{8}$ E todo esse sacrifício tendo como objetivo a causa política do Juazeiro e a devoção sertaneja.

Vale lembrar que as duas peças relacionam-se a outros textos. Lampião (1953) interliga-se às crônicas da autora, que têm o cangaço nordestino como tema; A Beata Maria do Egito liga-se à lenda cristã medieval, já mencionada, e à "Balada de Maria Egipcíaca”, escrita por Manuel Bandeira. Essa produção teatral foi explicada pela autora em crônica publicada na revista O Cruzeiro, intitulada "História de Beata", em 10 de outubro de 1959. Nessa crônica, Rachel comenta que sempre quisera escrever um texto em que o comportamento de uma pessoa Santa se debatesse com os "não santos". Escolhe a Santa medieval e adapta a história dela à cultura nordestina. Dessa forma, vemos que o teatro racheliano também passa pelo fio sertanejo que percorre a escrita de Rachel.

A autora, enquanto cronista, não foge do apego à terra, da defesa da liberdade e de trazer o ambiente cearense presente em todas as treze coletâneas editadas com textos que têm a cultura nordestina dando o tom, mesmo nos ambientes mais improváveis. Bom exemplo disso é a crônica “A caatinga gelada, réplica da nordestina.” Publicada em jornal dia 25 de dezembro de 1993, posteriormente organizada na coletânea Falso mar, falso mundo (2002), o texto expressa bem a busca da identificação com o sertão em qualquer espaço em que se encontrasse. Nessa crônica, Rachel de Queiroz compara a paisagem da cidade de Berlim, onde ela se encontrava, com a caatinga nordestina e conta o que vê:

(...) nem uma única folha, só galhos secos, garranchos agressivos no chão, o tapete das folhas secas escondendo a terra. E a neve, ainda fina, cobre como uma película os troncos do arvoredo tal como acontece com os pés de pau da caatinga, também brancos, fiéis ao seu nome indígena caa-tinga, ou seja, mato branco. ${ }^{9}$

Ao ocupar em 1945 a coluna “Última Página” da revista O Cruzeiro, Rachel de Queiroz já se revela, em sua primeira publicação, como aquela mulher que se delicia com o pouco que sua terra lhe oferece, mostrando-se adepta do quanto menos, mais. "Tem dia em que eu dava dez anos de vida por um pedacinho bem árido de caatinga, um riacho seco, um marmeleiral ralo, uma vereda pedregosa, sem nada de arvoredo luxuriante, nem lindos recantos de mar, (...)”10

\footnotetext{
${ }^{8}$ TAMARU. A construção literária da mulher nordestina em Rachel de Queiroz, p. 55.

${ }^{9}$ QUEIROZ. Falso mar, falso mundo, p. 59.

${ }^{10}$ QUEIROZ. Crônica n. 1.
} 
Em “Chuvas no Ceará”, crônica escrita em 1944 e que integra a primeira coletânea intitulada A donzela e a moura torta, a autora discorre sobre a notícia que veiculou na mídia da época, segundo a qual as chuvas, enfim, chegaram ao Ceará e que o governo já iniciara a distribuição de sementes àqueles lavradores renascidos pelas primeiras gotas de água, aspergindo o sertanejo com a esperança de um ano farto em que não faltasse comida no prato. Segue comentando e faz uma pausa para informar que há diferenças entre a seca de um espaço para outro dentro do próprio espaço sertanejo:

A região nordestina flagelada pelas secas é bem grande. Compreende vastas zonas de diversos estados e, segundo a natureza do local afetado, varia a "interpretação" que a terra dá ao flagelo (...). Nas regiões de serra, a seca chega até a ser um elemento de beleza (...). As flores continuam abrindo, as colheitas não morrem, os olhos d'água dificilmente secam $(. . .)^{11}$

Depois de apresentada essa distinção geográfica, Rachel prossegue, mostrando o sertão com riqueza de detalhes e profundo conhecimento de quem tem aquele solo como seu: “Mas, por fim, há o sertão. Aí, sim, é a pátria da seca, é o seu domínio, o seu império.”12

Para encerrar, a crônica “Um alpendre, uma rede, um açude”, publicada em agosto de 1944 e selecionada para participar da coletânea Cem crônicas escolhidas. Nesse texto, Rachel explicita, já pelo título, os ingredientes básicos para a vida do sertanejo: "Claro que esses três são apenas os termos essenciais: o alpendre é o abrigo, a rede o repouso, o açude a garantia de água e vida.” ${ }^{13}$

Ainda faz no decorrer do texto uma explanação da casa da fazenda com os elementos peculiares e ainda traça um calendário de afazeres sertanejos para todo o ano, fazendo um verdadeiro inventário de atividades e trazendo àqueles que não estão familiarizados com o cotidiano do sertão a oportunidade de se inserir nesse espaço, mesmo que de bem longe.

Dessa forma, evidencia-se que a presença do sertão na escrita de Rachel de Queiroz não se faz apenas por ser esse o seu tom de discurso ou por se inserir no seguimento regional, mas por ela ser testemunha dessa região e ser uma das escritoras que sempre se ocupou em divulgar o sertão, principalmente o sertão pobre, rude, seco, longe de um nordeste de engenhos, mas perto de um nordeste genuíno.

\footnotetext{
${ }^{11}$ QUEIROZ. A donzela e a Moura torta, p. 19.

${ }^{12}$ QUEIROZ. A donzela e a Moura torta, p. 20.

${ }^{13}$ QUEIROZ. Cem crônicas escolhidas, p. 51.
} 
A construção literária de Rachel de Queiroz está longe de ser pioneira na discussão de gênero ou de regionalismo, mas a partir de $O$ quinze, a Literatura Brasileira passou a contar com uma escrita feminina, cujo olhar surpreendeu e incomodou.

\begin{abstract}
Rachel de Queiroz's work has the hinterland as inspiration for the setting of her novel, chronicles or theater. Using the oral language and the portrayal of hinterland women and their past as a focus, Queiroz has constructed her reputation as a woman writer in Brazilian Literature and has contributed to the visibility of women's writing.
\end{abstract}

KEYWORDS

Rachel de Queiroz, feminile wrinting, hinterland

\title{
REFERÊNCIAS
}

ANDRADE, Mário. O empalhador de passarinho. 3. ed. São Paulo: Livraria Martins, 1972.

CADERNOS DE LITERATURA BRASILEIRA. Rachel de Queiroz. São Paulo: Instituto Moreira Sales, v. 4, set.1997.

DUARTE, Eduardo de Assis. Classe e gênero no romance de Rachel de Queiroz. In: Literatura, política, identidades. Belo Horizonte: Fale/UFMG, 2005. p. 105-112.

HAHNER, June. E. A mulher brasileira e suas lutas sociais e políticas: 1850-1937. São Paulo: Brasiliense, 1981.

QUEIROZ, Rachel de. Lampião. Rio de Janeiro: José Olympio, 1953.

QUEIROZ, Rachel de. História de beata. O Cruzeiro, ano 31, n. 52, 10 out. 1959.

QUEIROZ, Rachel de. A beata Maria do Egito. 2. ed. Rio de Janeiro: José Olympio, 1979.

QUEIROZ, Rachel de. As três Marias. Rio de Janeiro: José Olympio, 1989. (Obra reunida, v. 2)

QUEIROZ, Rachel de. Dôra, Doralina. Rio de Janeiro: José Olympio, 1989. (Obra reunida; v. 2)

QUEIROZ, Rachel de Cem crônicas escolhidas. Rio de janeiro: José Olympio, 1989. (Obra reunida; v. 4).

QUEIROZ, Rachel de A donzela e a Moura torta. Rio de Janeiro: José Olympio, 1989. (Obra reunida)

QUEIROZ, Rachel de. Caminho de pedras. 11. ed. São Paulo: Parma, 1990. (Coleção Aché dos imortais da Literatura Brasileira)

QUEIROZ, Rachel de. Memorial de Maria Moura. 9. ed. Rio de Janeiro: Siciliano, 1998. 
QUEIROZ, Rachel de. Falso mar, falso mundo. São Paulo: Arx, 2002.

QUEIROZ, Rachel de. O quinze. 77. ed. Rio de Janeiro: José Olympio, 2004.

TAMARU, Ângela Harumi. A construção literária da mulher nordestina em Rachel de Queiroz. 2004. 188f. Tese (Doutorado) - Universidade Estadual de Campinas, Campinas, 2004.

QUEIROZ, Rachel de. Crônica n. 1. O Cruzeiro, 1945. Coluna "Última Página”. Disponível em: <http://www.releituras.com/racheldequeiroz_cronica1.asp> Acesso: em: 22 out. 2010. 